\title{
Using Demographic and Health Surveys in the campaign to end FGM/C: A Kenyan example
}

\author{
Dennis Matanda \\ Population Council \\ Caroline W. Kabiru \\ Population Council
}

Follow this and additional works at: https://knowledgecommons.popcouncil.org/departments_sbsr-rh

Part of the Demography, Population, and Ecology Commons, Family, Life Course, and Society Commons, International Public Health Commons, Sociology of Culture Commons, and the Women's Health Commons How does access to this work benefit you? Let us know!

\section{Recommended Citation}

Matanda, Dennis and Caroline W. Kabiru. 2019. "Using Demographic and Health Surveys in the campaign to end FGM/C: A Kenyan example," Evidence to End FGM/C: Research to Help Girls and Women Thrive. New York: Population Council. 
The Evidence to End FGM/C programme consortium generates evidence to inform and influence investments, policies, and programs for ending female genital mutilation/ cutting in different contexts.

Population Council Lead Institution

Africa Coordination Centre for Abandonment of Female Genital Mutilation/Cutting, Kenya (ACCAF)

Global Research and Advocacy Group, Senegal (GRAG)

MannionDaniels Ltd. (MD)

Population Reference Bureau. (PRB)

University of Washington (Prof. Bettina Shell-Duncan) University of California, San Diego (Dr. Gerry Mackie)

Funded by

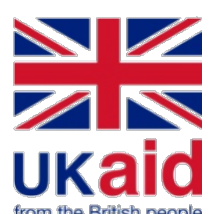

\section{USING DEMOGRAPHIC AND HEALTH SURVEYS IN THE CAMPAIGN TO END FGM/C: A KENYAN EXAMPLE}

\section{INTRODUCTION}

To design effective interventions to end $\mathrm{FGM} / \mathrm{C}$, we need to map where FGM/C is practised and what factors influence it. Data from the Demographic and Health Surveys (DHS), nationally representative surveys conducted in low- and middleincome countries every five years, give us the opportunity to explore how FGM/C is influenced by both individual and community-level factors.

Where $\mathrm{FGM} / \mathrm{C}$ prevalence is not uniform, various research and analysis techniques can be used to improve estimates and draw further information from DHS data.

In this brief, we share insights from two studies carried out in Kenya using DHS data collected in 1998, 2003, 2008 and 2014. The first study explored when, where and how FGM/C has been carried out, and trends in changes in the practice. The second examined geographic patterns for the burden of FGM/C and related risk factors among girls aged 0-14 years.

\section{METHODS}

In the first study, descriptive statistics were used to explore trends over time in FGM/C prevalence, and factors related to $\mathrm{FGM} / \mathrm{C}$. The second study used advanced Bayesian geo-additive modelling techniques to better understand the burden of $\mathrm{FGM} / \mathrm{C}$ among girls aged 0-14 years and to enhance knowledge of the geographic and socio-economic distribution of this practice over time.

\section{KEY LESSONS}

- Nationally

representative survey data on FGM/C in

Kenya are available

from four waves of

Demographic and

Health Surveys,

implemented in 1998,

2003, 2008-09, and

2014. These survey

data provide a rich

and detailed picture

of when, where, and

how FGM/C has been

carried out, and

trends in changes in

the practice.

- The research

methods used can be

adopted in other

countries to provide a

better understanding

of the geography and

patterns of FGM/C

over time.

- Findings from indepth analyses of DHS data can inform interventions; making them better targeted and more effective. 


\section{FINDINGS}

\section{What did we learn?}

Using all four rounds of data, the descriptive analysis showed a downward trend in national prevalence of FGM/C among 15- to 49-year-old women from 38 percent in 1998 to 21 percent in 2014. Prevalence across 5-year age cohorts showed a steady, long-term decline in rates of FGM/C that began in the early 1980's. However, the declines did not occur evenly among women from all ethnic groups with rates remaining very high among ethnic Somali women. Rates of FGM/C were high in older cohorts of Maasai and Kisii women but declined among younger cohorts of women. Other changes over time include a trend toward younger age at cutting and increased medicalisation (cutting performed by a health care professional as opposed to a traditional practitioner).

Bayesian geo-additive modelling using data for girls aged 0-14 years showed that whereas there is a national-level decline, the rates of decline have not been uniform across regions (Figure 1). The likelihood of FGM/C among girls was significantly higher if their mothers had no education, were Muslim, were from the Kisii or Somali ethnic communities, and lived in poorer households and in rural communities.

\section{What next?}

- Target interventions: By understanding where $\mathrm{FGM} / \mathrm{C}$ persists despite national level declines, DHS data can highlight potential sites for more intensive research and tailored interventions.

- Collect data over time: In communities where FGM/C persists, it would be helpful to conduct more in-depth research. This could include monitoring these counties to better understand prevalence, as well as collecting qualitative data to understand why FGM/C persists, sometimes in spite of targeted interventions.

- More research using the DHS in other settings: Taking advantage of multiple rounds of the DHS provided both trend analysis at the national level, as well as a more nuanced analysis of patterns within sub-groups. Bayesian geo-additive modelling using data for girls aged 0-14 years can help differentiate individual and community factors in $\mathrm{FGM} / \mathrm{C}$ abandonment. The exploration of FGM/C as a practice potentially maintained by both individual factors and collective social norms can be examined empirically with the increasingly rich body of survey data now available in other settings.

\section{FULL REPORTS AVAILABLE:}

1. Ngianga-Bakwin Kandala, Damaris Kinyoki, Ahmed Sarki, David Gathara, Paul Komba, and Bettina ShellDuncan. "Modelling and Mapping of Girls' Female Genital Mutilation/Cutting (FGM/C) in the context of economic, social, and regional disparities: Kenya Demographic and Health Surveys 1998-2014", May 2017, Evidence to End FGM/C: Research to Help Women Thrive. New York: Population Council.

2. Shell-Duncan, B., Gathara, D. and Moore, Z. "Female Genital Mutilation/Cutting in Kenya: Is Change Taking Place? Descriptive Statistics from Four Waves of Demographic and Health Surveys", February 2017, Evidence to End FGM/C: Research to Help Women Thrive. New York: Population Council.

\section{Suggested citation:}

"Using Demographic and Health Surveys in the Campaign to End FGM/C: A Kenyan Example," July 2019, Evidence to End FGM/C: Research to Help Women Thrive. New York: Population Council.

Figure 1. Predicted provincial FGM/C prevalence in Kenya 1998 to 2014 derived from spatial-temporal regression model
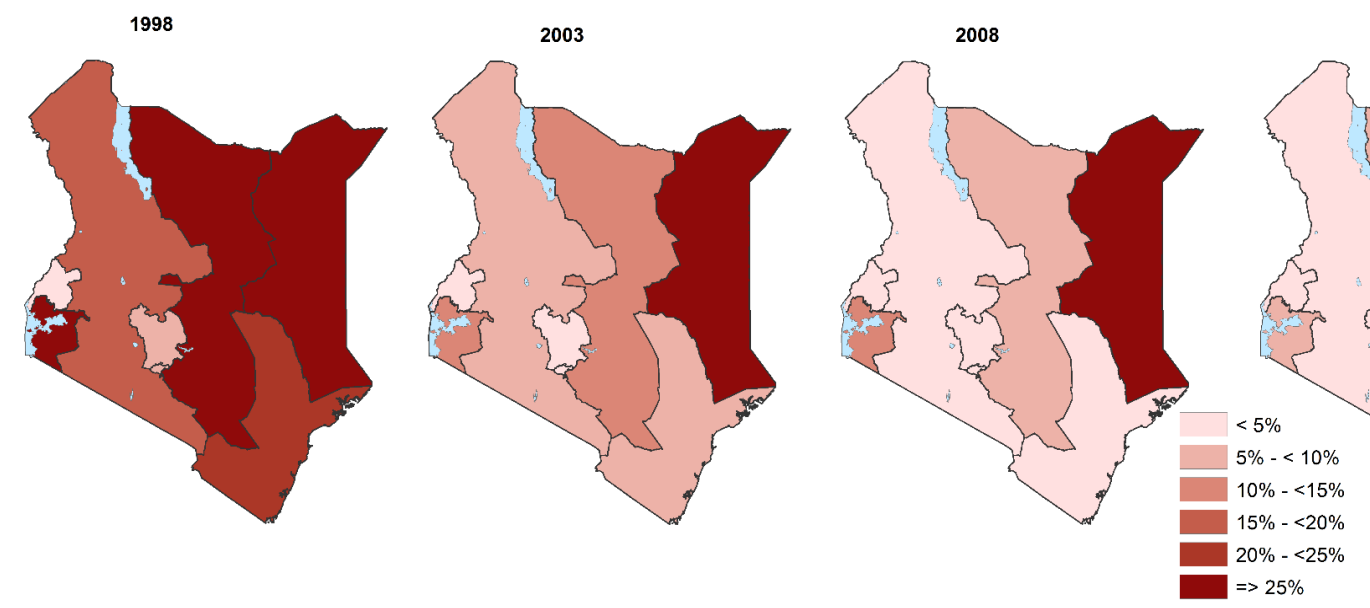

2014 